\title{
Insight into Acid-Base Nucleation Experiments by Comparison of the Chemical Composition of Positive, Negative, and Neutral Clusters
}

Federico Bianchi, ${ }^{\dagger}$ Arnaud P. Praplan, ${ }^{\ddagger}$ Nina Sarnela, ${ }^{\ddagger}$ Josef Dommen, ${ }^{\dagger}$ Andreas Kürten, ${ }^{\S}$ Ismael K. Ortega, ${ }^{\prime}$ Siegfried Schobesberger, ${ }^{\ddagger}$ Heikki Junninen, ${ }^{\ddagger}$ Mario Simon, ${ }^{\S}$ Jasmin Tröstl, ${ }^{\dagger}$

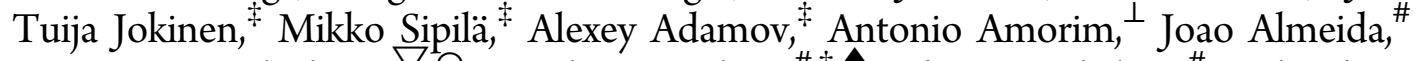
Martin Breitenlechner,,,$\bigcirc$ Jonathan Duplissy, ${ }^{\#, \pm}$ Sebastian Ehrhart, ${ }^{\#}$ Richard C. Flagan, ${ }^{\text {, }}$ Alessandro Franchin, ${ }^{,}$Jani Hakala, ${ }^{\ddagger}$ Armin Hansel, $\nabla, \bigcirc$ Martin Heinritzi, ${ }^{\$, \nabla}$ Juha Kangasluoma, ${ }^{*}$ Helmi Keskinen, ${ }^{+}$Jaeseok Kim, ${ }^{+}$Jasper Kirkby, ${ }^{\S, \#}$ Ari Laaksonen, ${ }^{+,} \bullet$ Michael J. Lawler, ${ }^{+, \$}$ Katrianne Lehtipalo, ${ }^{\ddagger} \%$ Markus Leiminger, ${ }^{\S}$ Vladimir Makhmutov, ${ }^{\&}$ Serge Mathot, ${ }^{\#}$ Antti Onnela, ${ }^{\#}$ Tuukka Petäjä, ${ }^{\ddagger}$ Francesco Riccobono, ${ }^{\dagger}$ Matti P. Rissanen, ${ }^{\ddagger}$ Linda Rondo, ${ }^{\S}$ António Tomé, ${ }^{\perp}$ Annele Virtanen, ${ }^{+}$Yrjö Viisanen, ${ }^{\bullet}$ Christina Williamson, ${ }^{\S}$ Daniela Wimmer, ${ }^{\ddagger}, \S$ Paul M. Winkler, $\diamond$ Penglin Ye,${ }^{\square}$ Joachim Curtius, ${ }^{\S}$ Markku Kulmala, ${ }^{\ddagger}$ Douglas R. Worsnop, ${ }^{+,}$Neil M. Donahue, ${ }^{\square}$ and Urs Baltensperger*, ${ }^{*}$

${ }^{\dagger}$ Laboratory of Atmospheric Chemistry, Paul Scherrer Institute, Villigen 5232, Switzerland

${ }^{\ddagger}$ Department of Physics, University of Helsinki, Helsinki 00014, Finland

${ }^{\S}$ Institute for Atmospheric and Environmental Sciences, Goethe University Frankfurt am Main, Frankfurt am Main 60438, Germany

"Laboratoire de Physique des Lasers, Atomes et Molécules, Université Lille 1 Sciences et Technologies, Villeneuve d'Ascq cedex 59655, France

${ }^{\perp}$ CENTRA-SIM, U. Lisboa and U. Beira Interior, Lisbon 1749, Portugal

${ }^{\#}$ CERN, Geneva 1211, Switzerland

$\nabla_{\text {University of Innsbruck, Innsbruck 6020, Austria }}$

OIONICON Analytik GmbH, Innsbruck 6020, Austria

Helsinki Institute of Physics, Helsinki 00014, Finland

${ }^{\text {II } C a l i f o r n i a}$ Institute of Technology, Pasadena, California 91125, United States

${ }^{+}$Department of Applied Physics, University of Eastern Finland, Kuopio 70211, Finland

\$Atmospheric Chemistry Division, National Center for Atmospheric Research, Boulder, Colorado 80301, United States

${ }^{\%}$ Airmodus Ltd, Helsinki 00560, Finland

\&Lebedev Physical Institute RAS, Leninsky prospekt, Moscow 119991, Russian

- Finnish Meteorological Institute, Helsinki 00101, Finland

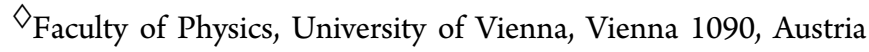

$\square$ Center for Atmospheric Particle Studies, Carnegie Mellon University, Pittsburgh, Pennsylvania 15213, United States

- Aerodyne Research Inc., Billerica, Massachusetts 01821, United States

Supporting Information

ABSTRACT: We investigated the nucleation of sulfuric acid together with two bases (ammonia and dimethylamine), at the CLOUD chamber at CERN. The chemical composition of positive, negative, and neutral clusters was studied using three Atmospheric Pressure interface-Time Of Flight (APi-TOF) mass spectrometers: two were operated in positive and negative mode to detect the chamber ions, while the third was equipped with a nitrate ion chemical ionization source allowing detection of neutral clusters. Taking into account the possible fragmentation that can happen continued...

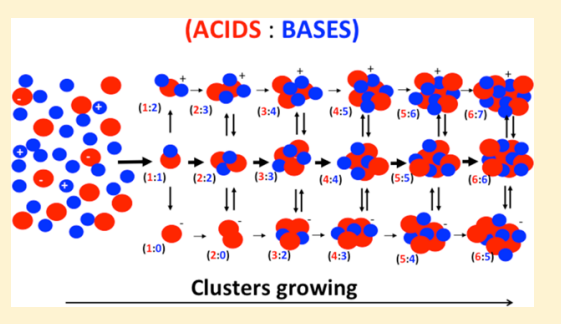

Received: May 14, 2014

Revised: September 25, 2014

Accepted: October 7, 2014

Published: November 18, 2014 
during the charging of the ions or within the first stage of the mass spectrometer, the cluster formation proceeded via essentially oneto-one acid-base addition for all of the clusters, independent of the type of the base. For the positive clusters, the charge is carried by one excess protonated base, while for the negative clusters it is carried by a deprotonated acid; the same is true for the neutral clusters after these have been ionized. During the experiments involving sulfuric acid and dimethylamine, it was possible to study the appearance time for all the clusters (positive, negative, and neutral). It appeared that, after the formation of the clusters containing three molecules of sulfuric acid, the clusters grow at a similar speed, independent of their charge. The growth rate is then probably limited by the arrival rate of sulfuric acid or cluster-cluster collision.

\section{INTRODUCTION}

Formation of new particles from the gas phase, also known as aerosol nucleation, has been observed in many places around the world. ${ }^{1-3}$ It has been estimated that $45 \%$ of the global cloud condensation nuclei (CCN) are derived from nucleation. ${ }^{4,5}$ Despite extensive research, the compounds participating in and governing this process remain uncertain. The CLOUD experiment based at CERN (Geneva, Switzerland) studies the nucleation process under variable conditions (temperature, relative humidity, ion concentration, precursor gas concentrations, etc.), which are relevant for the atmosphere. It is characterized by precise control of condensable vapor concentrations at or below atmospheric levels, precise control over ion pair production and removal, and extensive instrumentation to measure the number and composition of gases, clusters, and particles.

Many experiments to date have focused on sulfuric acid $\left(\mathrm{H}_{2} \mathrm{SO}_{4}\right),{ }^{6-8}$ ammonia $\left(\mathrm{NH}_{3}\right),{ }^{9-11}$ and dimethylamine (DMA, $\left.\left(\mathrm{CH}_{3}\right)_{2} \mathrm{NH}\right)^{12}$ as potentially atmospherically important reagents for these nucleation processes. Binary homogeneous nucleation (BHN) of sulfuric acid and water and ternary homogeneous nucleation (THN) involving ammonia, sulfuric acid, and water cannot explain the nucleation rates and growth rates observed in the planetary boundary layer. ${ }^{11,13,14} \mathrm{~A}$ computational study suggested that amines are more strongly bound to $\mathrm{H}_{2} \mathrm{SO}_{4}$ molecules than $\mathrm{NH}_{3}$ and can therefore enhance the neutral and ion-induced $\mathrm{H}_{2} \mathrm{SO}_{4} / \mathrm{H}_{2} \mathrm{O}$ nucleation in the atmosphere. ${ }^{15}$ Further experimental studies showed that dimethylamine could explain observed ambient nucleation rates, however, only at locations close to the emission sources of amines. ${ }^{16,17}$

In this study, we focus on the chemical composition of positively and negatively charged clusters as well as neutral clusters inside the chamber during the nucleation process. This was achieved using Atmospheric Pressure interface-Time Of Flight (APi-TOF) mass spectrometers, with and without a chemical ionization front end to charge neutral clusters. ${ }^{18}$ Using the same instrument, a recent study determined the chemical composition of the negative ions during experiments involving sulfuric acid, ammonia, dimethylamine, and oxidation products of pinanediol. ${ }^{19}$ The composition of ion clusters of sulfuric acid and ammonia during nucleation were also recently studied in detail. ${ }^{20}$ Another study made in the CLOUD experiment determined the chemical composition of neutral clusters during a nucleation experiment involving sulfuric acid and dimethylamine using a Chemical Ionization APi-TOF (CI-APi-TOF) mass spectrometer. $^{21}$

In experiments involving sulfuric acid and bases, the nucleation mechanism is driven by an acid-base chemical reaction. Measurements of positive ion clusters from ammonia-sulfuric acid revealed that $n$ molecules of sulfuric acid and $n+1$ molecules of ammonia compose the most stable positive clusters. ${ }^{22}$ The bond energy of sulfuric acid ammonia clusters was also calculated from the fragmentation energy. It was found that fragmentation of these clusters occurs by two pathways: either the clusters lose ammonia and sulfuric acid sequentially or the clusters lose directly one molecule of ammonium bisulfate. ${ }^{10}$ The stability of clusters of sulfuric acid with ammonia and/or dimethylamine is also an active field of research in computational chemistry. ${ }^{23,24}$

All of these studies suggest a particular cluster composition during nucleation experiments involving acids and bases. However, there is no work in the literature systematically exploring the composition for neutral and charged clusters of both polarities. Here we compare measurements of negatively and positively charged clusters as well as neutral clusters for BHN and for THN, where the latter includes two different bases (ammonia and dimethylamine).

\section{EXPERIMENTAL METHODS}

These experiments were conducted at the CLOUD chamber at CERN. The chemical composition of the positive, negative, and neutral clusters during nucleation experiments involving sulfuric acid, ammonia and dimethylamine was retrieved using three different APi-TOF (see Supporting Information and literature therein). Table 1 gives an overview of the nucleation experiments that were chosen for this cluster intercomparison. For each set of conditions that resulted in a certain composition of the clusters, we chose the experiment with the best quality of signal for all the instruments. When ammonia and DMA were intentionally added, the concentration of the base was always in excess compared to sulfuric acid. This is principally because it is very difficult to inject or to measure base concentrations that are below a few parts per trillion by volume.

\section{RESULTS}

This work describes the cluster composition of experiments involving an acid-base nucleation mechanism, where the acid is always $\mathrm{H}_{2} \mathrm{SO}_{4}$ and the bases are $\mathrm{NH}_{3}$ and DMA. The experiments and the composition of the ion clusters, in particular negative clusters, and some neutral clusters have been described elsewhere. ${ }^{11,16,19-21}$ Here, we present, for the first time to our knowledge, a comprehensive analysis for clusters of all polarities during new-particle formation, including neutral clusters.

Raw Mass Spectra for the Positive lons. We studied BHN involving $\mathrm{H}_{2} \mathrm{SO}_{4}$ and $\mathrm{H}_{2} \mathrm{O}$ and $\mathrm{THN}$ adding either ammonia (a weak base, proton affinity of $853.6 \mathrm{~kJ} \mathrm{~mol}^{-1}$ ) or dimethylamine (a stronger base, proton affinity of $929.5 \mathrm{~kJ} \mathrm{~mol}^{-1}$ ) as well as mixtures of the two bases. ${ }^{25}$ Figure 1 shows the mass spectra of the positive ions for these four types of experiments. For all of the data presented here, $\mathrm{SO}_{2}, \mathrm{O}_{3}$, and $\mathrm{H}_{2} \mathrm{O}$ were added to the chamber, and nucleation was triggered by switching on the UV light; photolysis of $\mathrm{O}_{3}$ in the presence of $\mathrm{H}_{2} \mathrm{O}$ produced $\mathrm{OH}$ radicals, which oxidized $\mathrm{SO}_{2}$ to $\mathrm{H}_{2} \mathrm{SO}_{4}$. Once a sufficiently high sulfuric acid concentration was reached, nucleation occurred. ${ }^{11}$ An important feature of the CLOUD chamber is that the lifetime of low-volatility vapors due to chamber wall loss $(\sim 10 \mathrm{~min})^{11}$ is similar to that found in the atmosphere, ${ }^{26}$ and so vapors and 
Table 1. Overview of Experiments ${ }^{a}$

\begin{tabular}{|c|c|c|c|c|c|c|c|}
\hline run no. & run type & {$\left[\mathrm{O}_{3}\right](\mathrm{ppbv})$} & {$\left[\mathrm{SO}_{2}\right](\mathrm{ppbv})$} & {$\left[\mathrm{NH}_{3}\right]$ (pptv) } & {$\left[\mathrm{C}_{2} \mathrm{H}_{7} \mathrm{~N}\right](\mathrm{pptv})$} & {$\left[\mathrm{H}_{2} \mathrm{SO}_{4}\right]\left(\mathrm{cm}^{-3}\right)$} & $J_{1.7}\left(\mathrm{~cm}^{-3} \mathrm{~s}^{-1}\right)$ \\
\hline 1016.01 & GCR & 85 & 62 & 18 & $<5$ & $1.7 \times 10^{8}$ & 71.3 \\
\hline 1027.03 & GCR & 13 & 62 & 11 & 7 & $9.3 \times 10^{6}$ & 3.8 \\
\hline 1042.01 & Beam & 23 & 62 & $<5$ & 20 & $4.5 \times 10^{6}$ & 163.6 \\
\hline 1047.01 & Neutral & 90 & 62 & 13 & 20 & $2.9 \times 10^{7}$ & 346.9 \\
\hline 1056.07 & Beam & 25 & 72 & $<5$ & $<5$ & $3.4 \times 10^{7}$ & 104.28 \\
\hline
\end{tabular}

${ }^{a}$ The run type describes the ion concentration conditions in the chamber (Neutral, no ions; GCR, ca. 400 ion pairs $\mathrm{cm}^{-3}$ formed by natural galactic cosmic rays; Beam, ca. 3000 ion pairs $\mathrm{cm}^{-3}$, mainly produced by the pion beam from CERN's proton synchrotron). Note that the detection limit for the DMA measurement was higher in these experiments than in previous ones, ${ }^{27}$ due to increased electrical noise. For a better comparison in all of these experiments, both temperature and relative humidity were kept constant at $5{ }^{\circ} \mathrm{C}$ and $38 \%$, respectively.

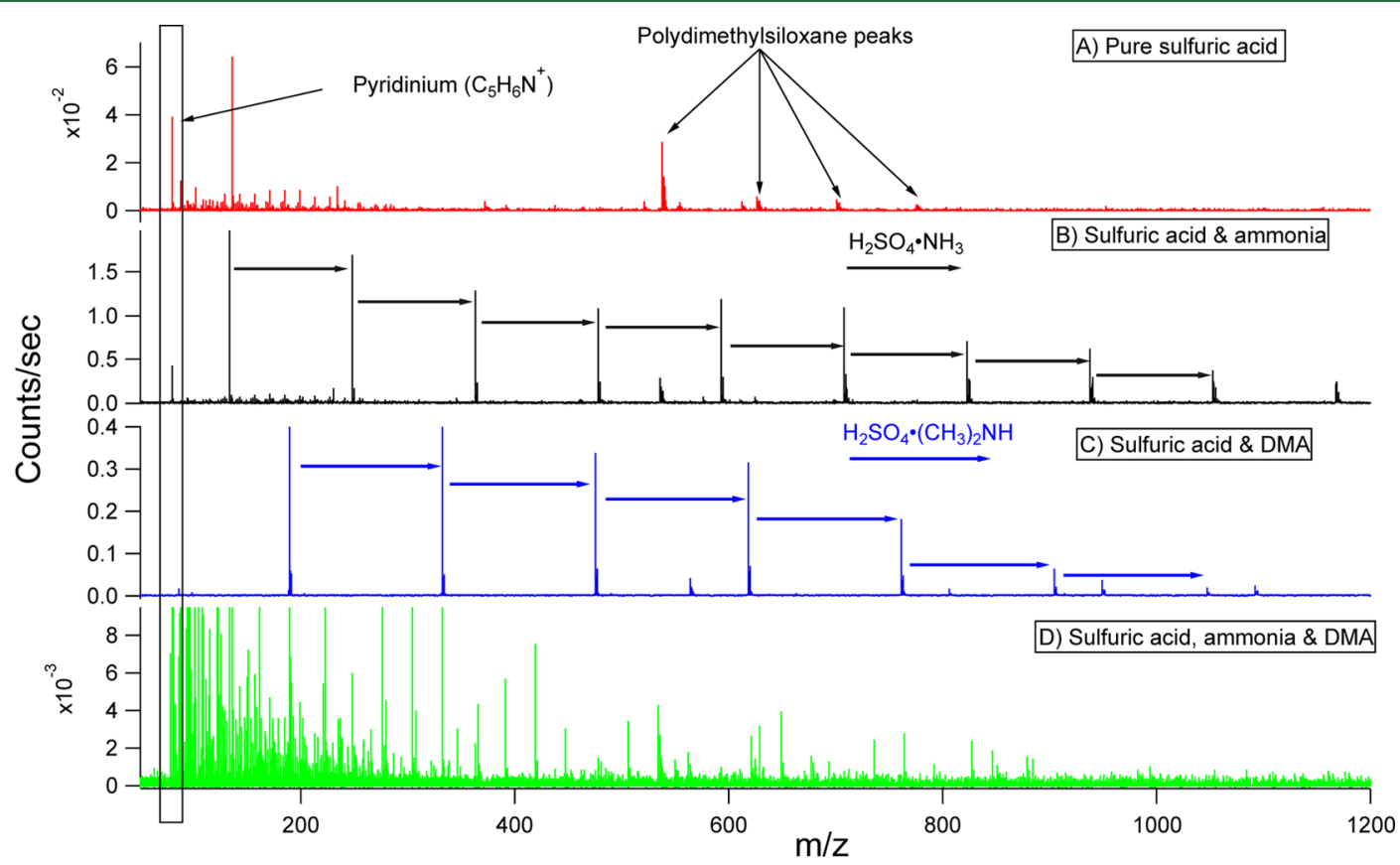

Figure 1. Mass spectra recorded with the APi-TOF(+) showing the positive ions of four nucleation experiments with different precursors. (A) Pure sulfuric acid, (B) with sulfuric acid and ammonia, (C) sulfuric acid and dimethyl amine (DMA), and (D) nominally pure sulfuric acid with impurities of ammonia and DMA from previous experiments. The silicone-related peaks in panel A are instrumental artifacts.

small clusters reach steady-state levels and experience condensational loss comparable to the real atmosphere. ${ }^{28,29}$

Figure $1 \mathrm{~A}$ presents the mass spectrum of an experiment involving $\mathrm{H}_{2} \mathrm{SO}_{4}$ and $\mathrm{H}_{2} \mathrm{O}$. However, even though the negative spectra showed sulfuric acid clusters containing up to $20 \mathrm{H}_{2} \mathrm{SO}_{4}$ molecules, the APi-TOF $(+)$ did not see any clusters; all of the main peaks consisted of impurities. The reason for this is the low proton affinity of $\mathrm{H}_{2} \mathrm{SO}_{4}$ clusters. Therefore, impurities present at extremely low concentrations but with a much higher proton affinity than sulfuric acid dominated the positive spectra; the positive charge had to go somewhere. The most intense peaks of the spectra were protonated pyridine $\left(\mathrm{C}_{5} \mathrm{H}_{6} \mathrm{~N}^{+}\right)$, other amines in the $\mathrm{m} / z$ range between 50 and 200 , and polydimethylsiloxane peaks between 500 and 800 . The polydimethylsiloxane peaks are instrumental artifacts, but they are useful peaks for mass calibration in the high $\mathrm{m} / z$ range. Figure $1 \mathrm{~B}$ shows the positive mass spectrum during a nucleation experiment involving ammonia and sulfuric acid (run 1016.01). It is well established that ammonia can enhance the nucleation by 1 or 2 orders of magnitude compared to a pure $\mathrm{H}_{2} \mathrm{SO}_{4}-\mathrm{H}_{2} \mathrm{O}$ experiment. ${ }^{9,11}$ The mass spectrum is simple and contains only a few evenly spaced peaks, which are mostly composed of only $\mathrm{H}_{2} \mathrm{SO}_{4}$ and $\mathrm{NH}_{3}$, with the exception of pyridine at the lower end of the spectrum. Figure $1 \mathrm{C}$ shows a nucleation experiment with sulfuric acid and DMA (run 1027.03). Also in this case, almost all of the peaks consist of $\mathrm{H}_{2} \mathrm{SO}_{4}$ and DMA, and the spectrum is even cleaner than in the $\mathrm{NH}_{3}$ case.

Following this set of experiments, only sulfuric acid was injected into the chamber. However, in spite of an overnight cleaning cycle $\left(100^{\circ} \mathrm{C}\right.$ for $\left.12 \mathrm{~h}\right)$, ammonia and DMA remained as impurities in the chamber, due to wall adsorption during the previous experiments, resulting in low (below 5 pptv, the detection limit of the ion chromatograph $)^{27}$ but still appreciable concentrations of $\mathrm{NH}_{3}$ and DMA. Consequently, the nucleation rate found in subsequent experiments was much higher than for the pure BHN experiments in the beginning of the campaign. The APi-TOF $(+)$ spectrum for this case is presented in Figure 1d (run 1056.07). Due to the low base concentrations, there are again substantially more impurities seen. However, all of the peaks that appear during nucleation consist of $\mathrm{H}_{2} \mathrm{SO}_{4}$ and bases (either $\mathrm{NH}_{3}$ or DMA or both). This demonstrates the critical importance of composition measurements during these experiments. Further details will be given in the discussion below.

Ammonia-Sulfuric Acid Experiments. A revealing way to present a mass spectrum is the mass defect plot. ${ }^{19,30}$ In those plots, the abscissa represents the measured $\mathrm{m} / \mathrm{z}$ of the compounds and the ordinate their mass defect, which is the difference between the accurate mass and the nominal mass (e.g., the 


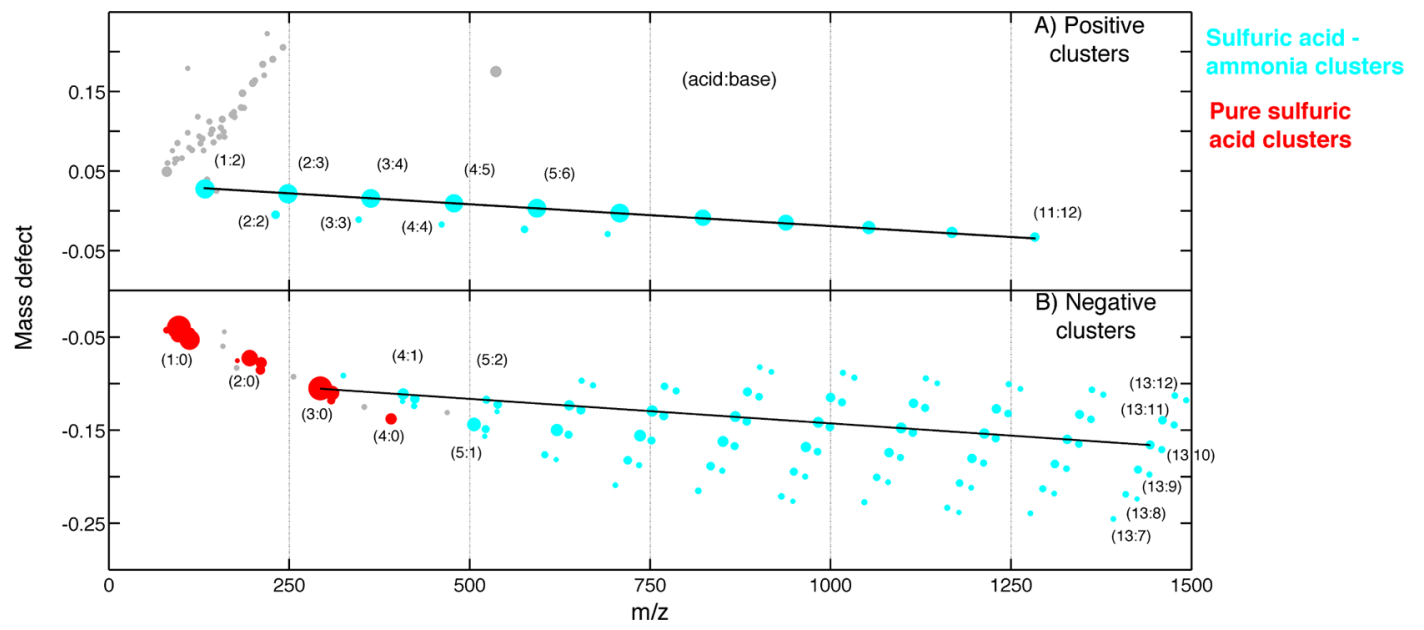

Figure 2. Mass defect plots of the positive ions (A) and negative ions (B) during an experiment where sulfuric acid and ammonia were present in the chamber (run 1016.01). The integration time for this experiment is $180 \mathrm{~min}$. The size of the symbols is proportional to the number of ions per cubic centimeter. Cyan circles represent clusters that are composed of sulfuric acid and ammonia; the red circles represent clusters that are only composed of sulfuric acid and related molecules (i.e., $\mathrm{SO}_{5}{ }^{-}, \mathrm{HSO}_{4}{ }^{-}, \mathrm{HSO}_{5}{ }^{-}$, etc.). The black lines that are drawn in both plots show clusters that are growing by a $1: 1$ acid-to-base addition. In the positive ions, the first cluster consists of one molecule of $\mathrm{H}_{2} \mathrm{SO}_{4}$ and two of ammonia plus a proton (1:2), whereas in the negative ions the first cluster to include ammonia is the sulfuric acid tetramer $(4: 1)$. The light blue negative cluster close to the pure sulfuric acid trimer is formed by two molecules of sulfuric acid, one of ammonia and $\mathrm{SO}_{5}{ }^{-}$.

exact mass of oxygen ${ }^{16} \mathrm{O}$ is $15.9949 \mathrm{Da}$ and its mass defect is thus $-0.0051 \mathrm{Da}$ ). In these plots, the symbol size is proportional to the peak intensity.

Figure 2 shows a comparison of the mass defect plots for the positive and negative ions for an $\mathrm{H}_{2} \mathrm{SO}_{4}-\mathrm{NH}_{3}$ experiment. Almost all of the ions are clusters composed of ammonia and sulfuric acid in the positive spectrum (panel A), with the exception of some minor peaks from impurities (mainly all identified) in gray color. Starting from the left of the mass spectrum, the first peak colored in cyan is composed of one molecule of $\mathrm{H}_{2} \mathrm{SO}_{4}$ and two molecules of $\mathrm{NH}_{3}$ with an additional proton $\left(\mathrm{H}^{+}\right)$. Following the black line, the compounds are formed by a near simultaneous addition of one sulfuric acid and one ammonia molecule.

The general formula for all of the main peaks in Figure $2 \mathrm{~A}$ falling on the black line is $\left(\mathrm{H}_{2} \mathrm{SO}_{4}\right)_{n}\left(\mathrm{NH}_{3}\right)_{n+1} \mathrm{H}^{+}$. A recent thermodynamic study shows that, according to quantum chemical calculations, the most stable positively charged sulfuric acid-ammonia clusters are those with this stoichiometry. ${ }^{31}$ However, we cannot exclude evaporation inside the mass spectrometer inlet (see Supporting Information). There are also some small cyan peaks shown just below the black line. These peaks are also composed only of $\mathrm{H}_{2} \mathrm{SO}_{4}$ and ammonia, but their stoichiometry differs slightly: $\left(\mathrm{H}_{2} \mathrm{SO}_{4}\right)_{n}\left(\mathrm{NH}_{3}\right)_{n} \mathrm{H}^{+}$. The positive ions suggest that the cluster growth mechanism is essentially a $1: 1$ addition of $\mathrm{H}_{2} \mathrm{SO}_{4}$ and $\mathrm{NH}_{3}$. In this experiment, the gas phase ammonia levels exceeded the sulfuric acid level, and therefore growth may have occurred by either the addition of sulfuric acid followed almost immediately by the addition of ammonia or by the addition of preformed neutral $\left(\mathrm{H}_{2} \mathrm{SO}_{4}\right)_{n}\left(\mathrm{NH}_{3}\right)_{n}$ clusters. However, these clusters are not so stable as suggested by the thermodynamic calculations. ${ }^{32,33}$ The weak signal with one less ammonia than standard is consistent with the first mechanism.

The negative clusters in Figure 2 (panel B) show similar features. The first negative clusters from the left (red dots) are composed only of sulfuric acid (monomer $\mathrm{m} / \mathrm{z} 97$, dimer $\mathrm{m} / \mathrm{z}$ 195 , trimer $m / z 293$, and tetramer $m / z$ 391); however, larger pure sulfuric acid clusters are absent. This can be explained by the fact that the bisulfate ion is a Lewis base; thus it is able to stabilize the sulfuric acid cluster in a similar way to other bases such as ammonia and amines. ${ }^{33}$ Small clusters with only a few sulfuric acid molecules allow for only one stabilizing base, while for large clusters more bases are possible. In the case of ammonia and amines, additional base molecules can be added to the cluster, but in the case of the bisulfate ion, the addition of a second bisulfate ion is not possible due to electrostatic repulsion, so in this case, the second base added to the cluster is ammonia. ${ }^{31}$ All of the clusters larger than $400 \mathrm{Th}$ are composed of $\mathrm{H}_{2} \mathrm{SO}_{4}$ and $\mathrm{NH}_{3}$.

While in positive clusters the protonated base always carries the charge, in the negative case every type of cluster gets its charge from two different compounds: $\mathrm{HSO}_{4}{ }^{-}$or $\mathrm{HSO}_{5}{ }^{-20} \cdot{ }^{20}$ Also, for the negative ions, the ratio between $\mathrm{H}_{2} \mathrm{SO}_{4}$ and $\mathrm{NH}_{3}$ is close to one, but the distribution of the clusters is broad, whereas in the positive case the distribution is very narrow. For example, the negative clusters containing eight $\mathrm{H}_{2} \mathrm{SO}_{4}$ molecules have two to seven $\mathrm{NH}_{3}$ molecules. The main sequence, marked with a black line, has the formula $\left(\mathrm{H}_{2} \mathrm{SO}_{4}\right)_{n}\left(\mathrm{NH}_{3}\right)_{n-3} \mathrm{HSO}_{4}{ }^{-}$or $\left(\mathrm{H}_{2} \mathrm{SO}_{4}\right)_{n}\left(\mathrm{NH}_{3}\right)_{n-3} \mathrm{HSO}_{5}{ }^{-}$. This is again consistent with growth governed by sulfuric acid addition but a broader stability range for base (ammonia) content.

One of the possible reasons for the wider distribution of negatively charged clusters compared to positively charged clusters may be the greater stability of clusters with the same number of sulfuric acid molecules but different numbers of ammonia molecules for negatively charged sulfuric acidammonia clusters compared to the positively charged ones. For example, in the case of $\left(\mathrm{H}_{2} \mathrm{SO}_{4}\right)_{4}\left(\mathrm{NH}_{3}\right)_{\mathrm{n}} \mathrm{HSO}_{4}^{-}$clusters, the most stable one has $n=3\left(k_{\text {evap }}=6.9 \times 10^{-3} \mathrm{~s}^{-1}\right)$, but clusters with $n=1$ or 2 are relatively close in stability $\left(k_{\text {evap }}=1.2 \mathrm{~s}^{-1}\right.$ and $k_{\text {evap }}=2.5 \times 10^{-1} \mathrm{~s}^{-1}$, respectively), while when $n=4$, the number of bases in the cluster (counting also $\mathrm{HSO}_{4}{ }^{-}$as a base) is larger than the number of acid molecules and the cluster becomes less stable $\left(k_{\text {evap }}=2.3 \times 10^{9} \mathrm{~s}^{-1}\right) \cdot{ }^{31}$ In the case of positively charged clusters, the difference between the most stable cluster for a certain number of sulfuric acid molecules and the rest is larger. For example, in the case of $\left(\mathrm{H}_{2} \mathrm{SO}_{4}\right)_{2}\left(\mathrm{NH}_{3}\right)_{n} \mathrm{NH}_{4}{ }^{+}$clusters, the most stable cluster is the one with $n=2\left(k_{\text {evap }}=1.7 \times 10^{-5} \mathrm{~s}^{-1}\right)$. In this case, the cluster with the second highest stability is the one 


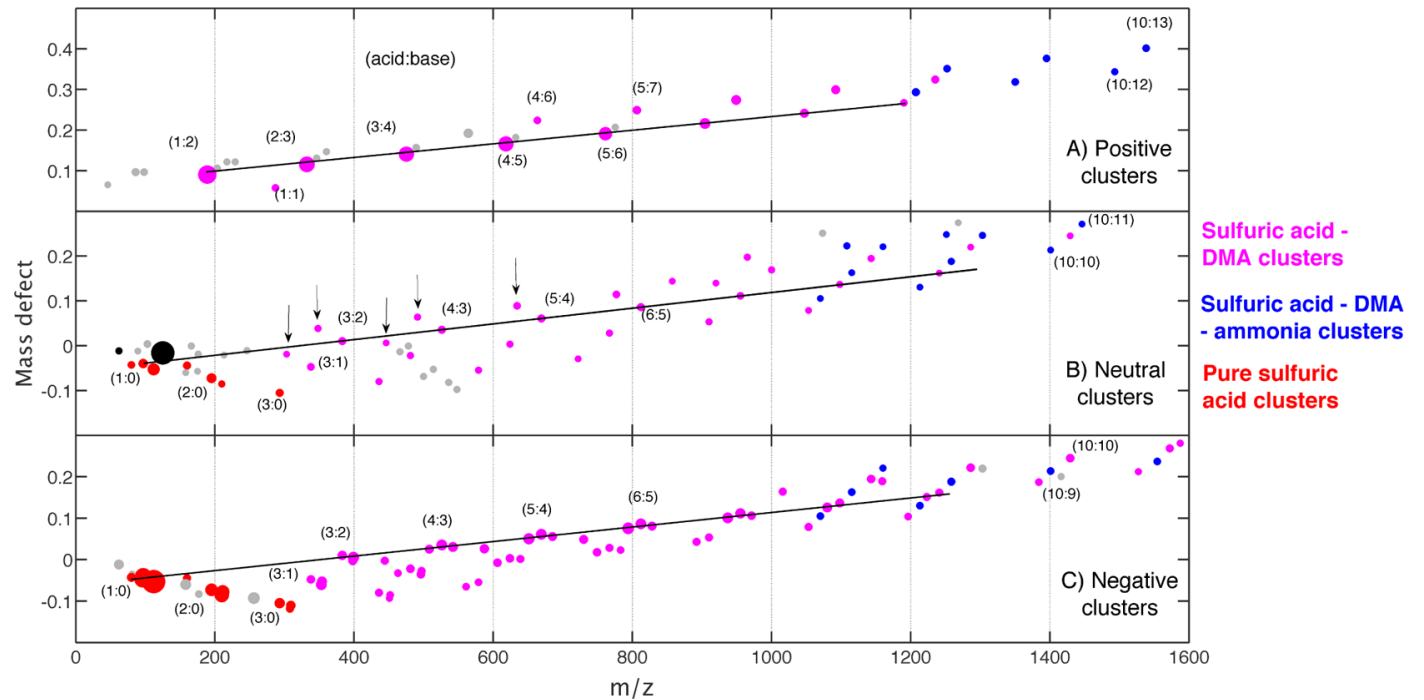

Figure 3. Mass defect plots of the positive clusters (panel A, run 1027.03), neutral clusters (panel B run 1047.01) and negative clusters (panel C run 1027.03) during an experiment where $\mathrm{H}_{2} \mathrm{SO}_{4}$ and DMA were present in the chamber. The mass spectra are all integrated for 120 min. The size of the peaks is proportional to the number of ions per cubic centimeter. The pink color represents clusters that are composed of $\mathrm{H}_{2} \mathrm{SO}_{4}$ and DMA. The red color represents clusters that are only composed of sulfur species. The blue color shows all the clusters that contain $\mathrm{NH}_{3}, \mathrm{H}_{2} \mathrm{SO}_{4}$, and DMA. The black dots in panel B are nitrate clusters that are the primary ions of the CI-APi-TOF. The black line shows the clusters that grow with a 1:1 acid base addition. Symbols with arrows are examples for clusters where bisulfate is substituted by nitrate in the CI process.

with $\left.n=1 k_{\text {evap }}=8.0 \times 10^{-1} \mathrm{~s}^{-1}\right)$; clusters with $n=0$ and 3 are less stable $\left(k_{\text {evap }}=1.8 \times 10^{2} \mathrm{~s}^{-1}\right.$ and $k_{\text {evap }}=1.2 \times 10^{4} \mathrm{~s}^{-1}$, respectively). ${ }^{31}$ It is important to recall that cluster formation is a kinetic process, where the cluster distribution depends not only on the stability of different clusters but also in the concentration of the precursors, with higher ammonia concentrations resulting in a higher $\mathrm{NH}_{3} / \mathrm{H}_{2} \mathrm{SO}_{4}$ ratio in the clusters. ${ }^{20,32}$ Furthermore, there are additional factors that might affect the observed cluster distribution, like the possible loss of weakly bound molecules from the cluster inside the instrument, or the existence of a kinetic barrier for the incorporation of ammonia. ${ }^{10}$ For example, in the case of the negatively charged pentamer discussed above, the most stable cluster contains three ammonia molecules, while the most abundant negatively charged pentamer observed contains one. However, evaporation inside the instrument cannot be excluded.

Another interesting issue found using an instrument measuring the hygroscopic properties of nucleated particles is that, when ammonia is present in excess, sulfuric acid is almost always completely neutralized (1:2 acid/base ratio) by the time particles grew to $20-50 \mathrm{~nm}$ diameter during nucleation events, typically as ammonium sulfate. ${ }^{34}$ The gradual addition of extra base molecules likely represents the onset of this change in composition, but the transition from a bisulfate composition for the smallest clusters to a sulfate composition for larger particles has yet to be completely explained.

Dimethylamine-Sulfuric Acid Experiments. DMA is a much stronger base than $\mathrm{NH}_{3}$, and the nucleation rates with DMA were much higher than in the $\mathrm{NH}_{3}$ experiments. ${ }^{16}$ These experiments have much higher steady-state concentrations of small particles than the $\mathrm{NH}_{3}$ experiments. This is because the steady-state cluster concentrations are controlled in part by loss via condensational growth, and for a comparable nucleation rate the DMA experiments have significantly lower sulfuric acid vapor concentrations, lower growth rates, and thus higher concentrations of individual clusters. This leads to a better signal-tonoise ratio, which is fundamental for the detection of neutral clusters with the CI-APi-TOF. These peculiarities are also the reason why it is possible to study the cluster time evolution shown below. Unfortunately, it was not possible to retrieve the chemical composition of the neutral clusters in the $\mathrm{NH}_{3}$ case. As noted above, the formation rate of new particles, at the same sulfuric acid concentrations, is much higher in the presence of DMA than with $\mathrm{NH}_{3}$. Another possibility is that the $\mathrm{H}_{2} \mathrm{SO}_{4}-\mathrm{NH}_{3}$ clusters fall apart after the collision with the primary ions, while in the dimethylamine case, this does not happen due to the high stability of those clusters. However, the negative APi-TOF composition as well as direct observation of neutral $\mathrm{H}_{2} \mathrm{SO}_{4}-\mathrm{NH}_{3}$ at higher vapor concentrations make this unlikely. ${ }^{35}$

In Figure 3, we show three mass defect plots from nucleation experiments with DMA and $\mathrm{H}_{2} \mathrm{SO}_{4}$. The positive and negative ions are from the same experiment (pion beam run 1027.03), while for the CI-APi-TOF a run with the clearing field on was used where all of the clusters in the chamber were neutral (run 1047.01).

Panel A in Figure 3 shows the positive ions, which strongly resemble those in the ammonia case. The only difference is that $\mathrm{NH}_{3}$ is replaced by DMA. The main clusters are located along the black line and have the same general formula as in the ammonia experiments: $\left(\mathrm{H}_{2} \mathrm{SO}_{4}\right)_{n}\left(\left(\mathrm{CH}_{3}\right)_{2} \mathrm{NH}\right)_{n+1} \mathrm{H}^{+}$. It should be noted that the peaks related to impurities in the ammonia experiments are not present anymore or are at very low intensity. The most probable reason for this discrepancy is that the proton affinity of DMA is higher than that of ammonia. This means that impurities are less likely to acquire and keep a positive charge. As an example, it can be seen that during the nucleation experiments with DMA the pyridine peak is much smaller. Unlike the $\mathrm{NH}_{3}$ case, there is only one cluster where the number of acids and number of bases is the same. This is the cluster at $289 \mathrm{Th}$ (2 sulfuric acid and 2 DMA molecules). On the other hand, above $600 \mathrm{Th}$, there are many clusters containing one extra DMA, which is not observed in the ammonia experiments. The possible explanation is that sulfuric acid-DMA clusters with two more DMA than sulfuric acid molecules are relatively stable; 


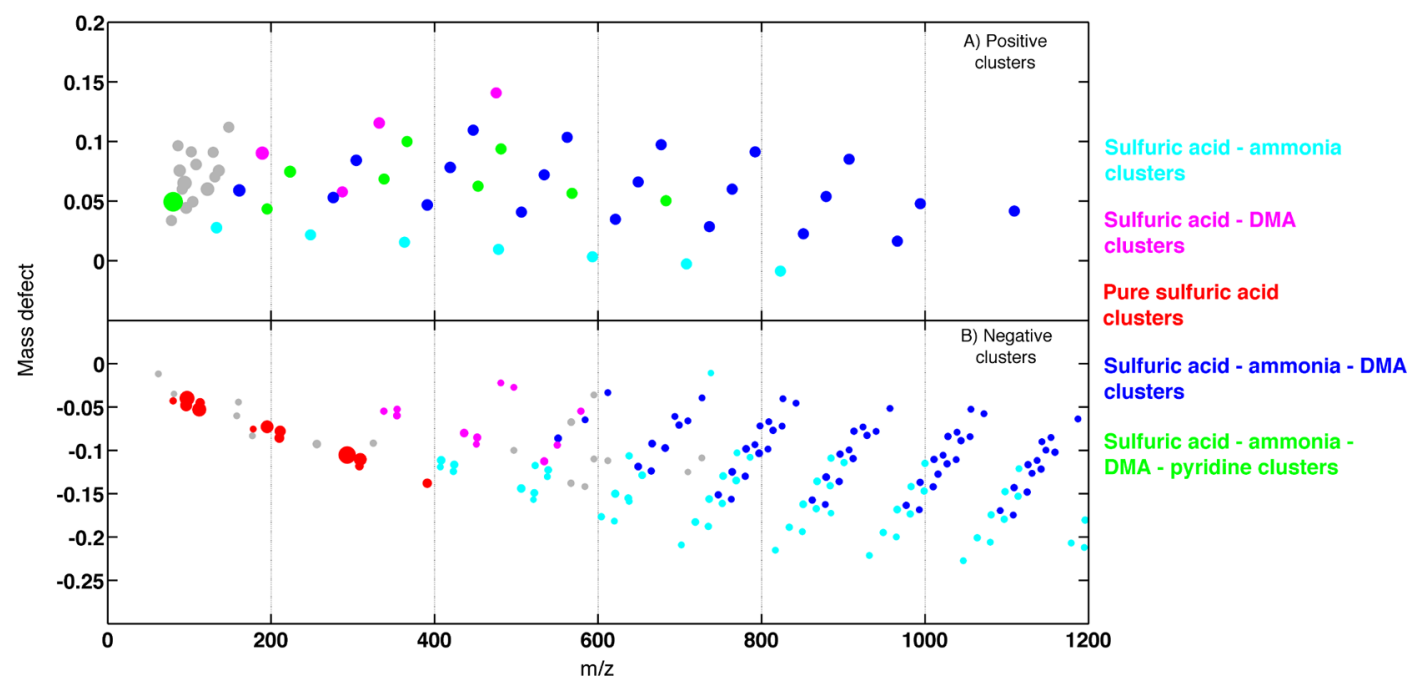

Figure 4. Mass defect plots of the positive clusters (panel A) and negative clusters (panel B) during an experiment where only $\mathrm{SO}_{2}, \mathrm{O}_{3}$, and $\mathrm{H}_{2} \mathrm{O}$ were intentionally added to the chamber, but previously added $\mathrm{NH}_{3}$ and DMA were still present as contaminants/impurities (run 1056.07). The integration time for these mass spectra is $180 \mathrm{~min}$. The size of the peaks is proportional to the number of ions per cubic centimeter. The pink color represents clusters that are composed of $\mathrm{H}_{2} \mathrm{SO}_{4}$ and DMA; the red colors represent clusters that are only composed of sulfur species; the cyan color represents $\mathrm{H}_{2} \mathrm{SO}_{4}-\mathrm{NH}_{3}$ clusters, and the dark blue color represents clusters that contain $\mathrm{H}_{2} \mathrm{SO}_{4}, \mathrm{NH}_{3}$, and DMA. In addition to these clusters, there is another family of clusters characterized by the green color. These clusters contain $\mathrm{H}_{2} \mathrm{SO}_{4}, \mathrm{NH}_{3}, \mathrm{DMA}$, and pyridinium $\left(\mathrm{C}_{5} \mathrm{H}_{6} \mathrm{~N}^{+}\right)$as a charged ion.

for example the $\left(\mathrm{H}_{2} \mathrm{SO}_{4}\right)_{2}\left(\left(\mathrm{CH}_{3}\right)_{2} \mathrm{NH}_{3}\right)_{4} \mathrm{H}^{+}$cluster has an evaporation rate of $1.4 \times 10^{-2} \mathrm{~s}^{-1} .31$

Panel C in Figure 3 shows the chemical composition of the negative ions for the same experiment (run 1027.03). Also in this case, the first clusters appearing are formed by pure $\mathrm{H}_{2} \mathrm{SO}_{4}$ where the charging ions can be $\mathrm{SO}_{5}{ }^{-}, \mathrm{HSO}_{4}{ }^{-}$, or $\mathrm{HSO}_{5}{ }^{-}$, while in the $\mathrm{NH}_{3}$ experiments there were only two charging ions $\left(\mathrm{HSO}_{4}{ }^{-}\right.$and $\left.\mathrm{HSO}_{5}{ }^{-}\right)$. Therefore, the mass defect plots in the DMA case are more complex than in the $\mathrm{NH}_{3}$ case. The first cluster containing DMA is formed by three acids and one DMA, while in the $\mathrm{NH}_{3}$ case four acids are needed before a base is detected in the negative clusters. After that, the growth proceeds with a 1:1 addition of $\mathrm{H}_{2} \mathrm{SO}_{4}$ and DMA. As with ammonia, the negative peaks show a variety of acid/base stoichiometric ratios but with an increasing number of base molecules per acid with increasing cluster size.

Panel B in Figure 3 shows the composition of the neutral clusters. These clusters were ionized by a reaction with a primary ion $\left(\mathrm{HNO}_{3}\right)_{(0-2)} \mathrm{NO}_{3}{ }^{-}$in the chemical ionization unit as explained before. Once these clusters are ionized it is remarkable that the composition of negative and neutral clusters is practically the same. Besides the difference of the two systems, the mechanism leading to the negatively charged ions in the chamber is similar to the charging process of the neutral clusters in the chemical ionization unit.

It is also important to note that charging of a neutral cluster leads to the evaporation of base molecules for the smallest clusters. ${ }^{31}$ This effect has been observed for neutral nucleating clusters measured with the CI-APi-TOF in the system of sulfuric acid and dimethylamine. ${ }^{21}$

Dimethylamine-Ammonia-Sulfuric Acid Experiments. Figure 4 shows the chemical composition of the ions for an experiment involving $\mathrm{H}_{2} \mathrm{SO}_{4}, \mathrm{NH}_{3}$, and DMA clusters. As mentioned above, no bases were intentionally added in this experiment, but the chamber still contained traces of them from the previous experiments. Once again the positive ions (panel A) show similar features, with a 1:1 acid-base addition. The general formula for the main peaks is $\left(\mathrm{H}_{2} \mathrm{SO}_{4}\right)_{n}(\text { Base })_{n+1} \mathrm{H}^{+}$, where Base indicates either $\mathrm{NH}_{3},\left(\left(\mathrm{CH}_{3}\right)_{2} \mathrm{NH}\right)$, or $\mathrm{C}_{5} \mathrm{H}_{5} \mathrm{~N}$ (pyridine). However, there are different types of clusters. As before, the clusters marked in cyan are only composed of $\mathrm{H}_{2} \mathrm{SO}_{4}$ and $\mathrm{NH}_{3}$, and the pink clusters are only composed of sulfuric acid and DMA (same as the previous experiments). In addition to these two types, all of the other growing clusters are formed by $\mathrm{H}_{2} \mathrm{SO}_{4}$ and a combination of $\mathrm{NH}_{3}$ and DMA (blue dots).

The data in Figure 4 underline once more that in these experiments the main mechanism for new-particle formation is an acid-base reaction. However, in this run, a new type of cluster appeared. These clusters are composed of the same compounds as the clusters marked in blue, but they contain in addition one molecule of pyridine (green color). During this experiment, the protonated pyridine (pyridinium) was present at a relatively high concentration. In the APi-TOF range, it is the most abundant ion present in the positive mode (first green dot on the left of the mass spectrum). The most likely explanation is that the other bases were present at much lower concentrations than in the previous experiments. This low competition situation allows pyridine to get protonated. These data show that pyridinium is able to charge the neutral SA-DMA- $\mathrm{NH}_{3}$ clusters, without playing a role in the growth process. One possible explanation is the steric hindrance of pyridine that does not allow another pyridine to join the cluster. In this type of experiment, the positive ions are not anymore dominated by the nucleating acid base clusters; there are also a lot of ions that do not participate in the particle growth process. These are probably ions that are present as contaminants, and they are at low $\mathrm{m} / z$ (gray color).

Regarding the negative ions (panel $\mathrm{B}$ ), the cluster formation is driven by $\mathrm{H}_{2} \mathrm{SO}_{4}, \mathrm{NH}_{3}$, and DMA. Here, numerous pure $\mathrm{H}_{2} \mathrm{SO}_{4}-\mathrm{NH}_{3}$ clusters and also more $\mathrm{H}_{2} \mathrm{SO}_{4}$-DMA clusters than in the positive case are present, but the clusters that grow all the way to the upper end of the spectra are composed of $\mathrm{H}_{2} \mathrm{SO}_{4}$, $\mathrm{NH}_{3}$, and DMA (blue dots). Once again, the nucleation process is essentially driven by a 1:1 acid-base addition. The only difference is that pyridine is absent in the negative ions. This can be another indication that pyridine is not helping the growth of 


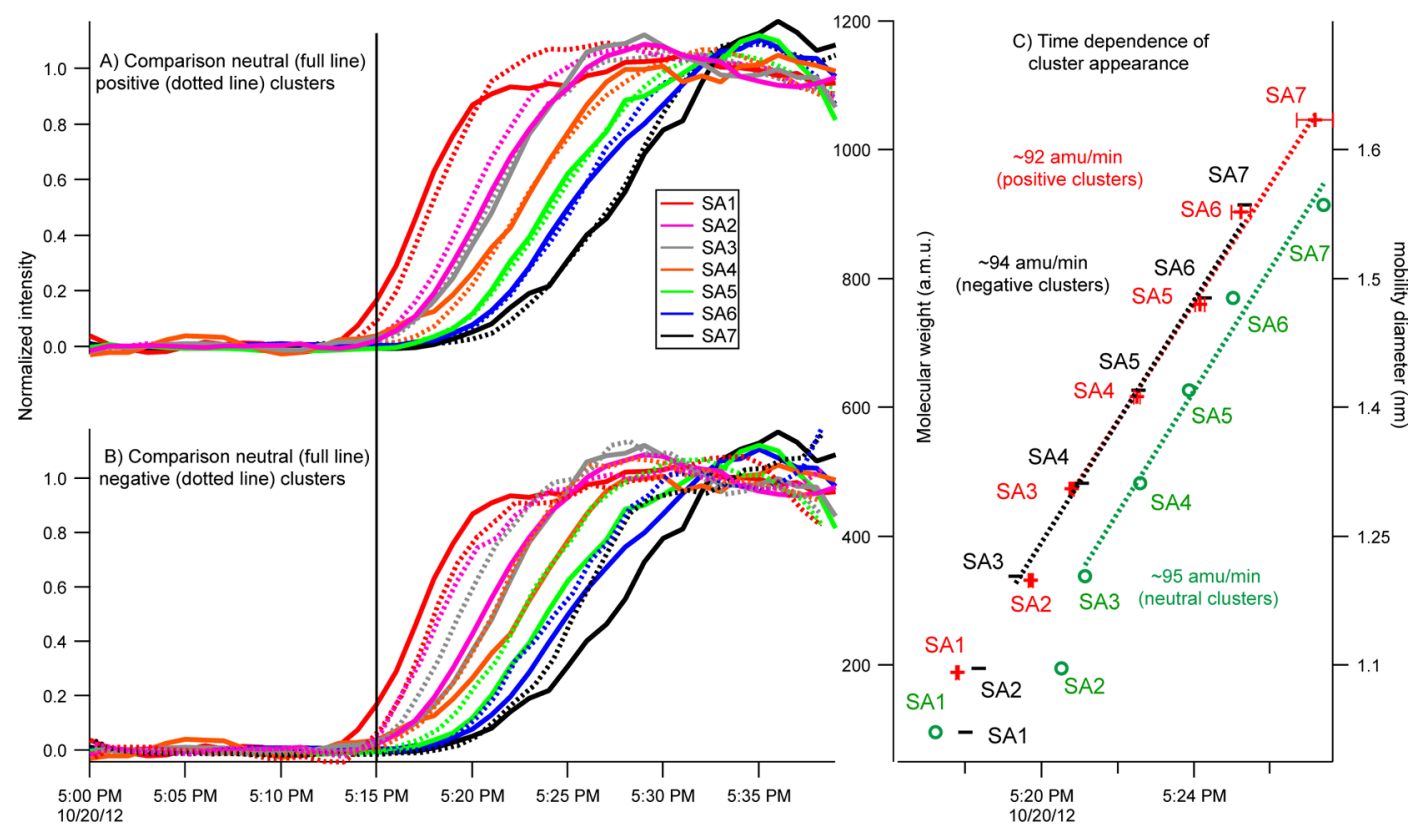

Figure 5. Time evolution of cluster concentrations (normalized to the steady-state level) during an experiment with sulfuric acid and dimethyl amine (panel A and B, run 1042.01). For the time-evolution analysis, spectra were averaged in 30-s intervals. The black line at 5:15 pm shows the time when the light was switched on. The rising before this point is due to the smoothing. Panel A shows the comparison between positive ions (dotted line) and the neutral clusters (solid line) and panel B the comparison between negative ions (dotted line) and neutral clusters (solid line). Panel C shows the molecular weight of the clusters (a.m.u.) retrieved by APi-TOF versus time, based on the $50 \%$ appearance times from the left-hand panels using the three different mass spectrometers. To give an estimate of the size of these clusters, we added a second axis showing the approximate mobility diameter (blue), which was calculated using a density of $1600 \mathrm{~kg} / \mathrm{m}^{3}$ and following a method used previously. ${ }^{1,36}$ Each dot in the right panel corresponds to one series of cluster (e.g., all the clusters containing six sulfuric acid molecules). The error bars $(1 \sigma)$ are calculated based on the effect of the choice of the steady state level on the $50 \%$ appearance time and are indicative for all three mass spectrometers.

the particles, but it is just the charging ion that allows a neutral cluster to be detected by the APi-TOF $(+)$.

Appearance Time of Freshly Nucleated Clusters. As mentioned above, for the experiments with DMA, the signal-tonoise ratio was very good for all three instruments. Integration of the mass spectra over just $30 \mathrm{~s}$ yielded a suitable signal, which allowed us to track the time evolution of the clusters. These results provide additional information about the possible mechanisms involved in the nucleation and growth process for the ions and the neutral clusters. Appearance times were also presented for nucleation experiments involving sulfuric acid and oxidation products of pinanediol. ${ }^{37}$ Figure 5 shows the time series of the main clusters in an $\mathrm{H}_{2} \mathrm{SO}_{4}$-DMA experiment. Panels $\mathrm{A}$ and $\mathrm{B}$ compare the appearance times of the negative and positive ions, respectively, with that of the neutral clusters (all from run 1042.01). All traces are normalized to their (long time) steadystate levels, and the appearance time is defined as the time when the signal reaches $50 \%$ of its steady-state value. The notation SA1, SA2, SA3, SA4, SA5, SA6, and SA7 refers to the number of sulfuric acid molecules that are present in the clusters. For example, SA6 is the sum of the signal of all clusters containing six sulfuric acid molecules considering $\mathrm{HSO}_{4}^{-}$as one molecule of sulfuric acid.

The formation of these clusters starts with the onset of photochemistry, which triggers the oxidation of $\mathrm{SO}_{2}$ to $\mathrm{H}_{2} \mathrm{SO}_{4}$. Therefore, the first peak that rises is from neutral sulfuric acid (red solid line). The acid forms an adduct with DMA and more sulfuric acid molecules are added sequentially. As expected, clusters containing $n+1 \mathrm{H}_{2} \mathrm{SO}_{4}$ molecules always follow directly to the clusters containing $n \mathrm{H}_{2} \mathrm{SO}_{4}$ molecules. However, there are some differences in the time evolution of these clusters.

In this experiment, the appearance time of the growing cluster is governed by the collision rate of $\mathrm{H}_{2} \mathrm{SO}_{4}$, since DMA is in excess
(100 times higher than SA) and attaches at a much shorter time scale. $^{21}$

While positive and neutral clusters have apparently similar time evolution from the formation of the first cluster onward, the negative ions behave quite differently. Once the first negative cluster $\left(\mathrm{HSO}_{4}{ }^{-}\right)$is formed, the negative ions appear relatively quickly until they contain three molecules of sulfuric acid (SA3). This high initial appearance rate is not seen in the positive ions. After the formation of SA3, however, it is important to note that the growth rate $(\mathrm{amu} / \mathrm{min})$ is practically the same for the three different instruments. This suggests that the growth process is kinetically limited by the arrival rate of sulfuric acid as shown by Kürten et al. for the neutral clusters. ${ }^{21}$ It is expected that the ions have a much higher collision rate than neutrals; however this is not seen in these data except for the smallest negative clusters. One possible reason is that the ion enhancement of the collision rates decreases rapidly with the size of the clusters. ${ }^{38}$ Formation of neutral clusters by ion-ion recombination is another possible explanation. ${ }^{39}$ Also, steady-state appearance times will be close together when there is significant evaporation limiting cluster lifetimes. Finally, it should also be noted that Kürten et al. [ref 21] included an enhancement factor of 2.3 due to London-van der Waals forces ${ }^{40}$ for the collision rate of neutral SA.DMA clusters, which leads to an overall collision rate on the order of $10^{-9} \mathrm{~cm}^{3} \mathrm{~s}^{-1}$. This is close to the ion-neutral molecule collision rate.

Looking at the difference between positive and negative ions, it could be speculated that, since the positive ions containing $n$ molecules of sulfuric acid appear at the same time as negative clusters containing $n+1$ molecules of sulfuric acid, the positive clusters lose one molecule of sulfuric acid once they enter the APi-TOF. This would imply that a measured positive cluster like $\left(\mathrm{H}_{2} \mathrm{SO}_{4}\right)_{n}\left(\mathrm{C}_{2} \mathrm{H}_{7} \mathrm{~N}\right)_{n} \mathrm{C}_{2} \mathrm{H}_{8} \mathrm{~N}^{+}$would have been formed from 
$\left(\mathrm{H}_{2} \mathrm{SO}_{4}\right)_{n+1}\left(\mathrm{C}_{2} \mathrm{H}_{7} \mathrm{~N}\right)_{n} \mathrm{C}_{2} \mathrm{H}_{8} \mathrm{~N}^{+}$. However, quantum chemical calculations show that these clusters with an extra sulfuric acid are much less stable. ${ }^{31}$ Another explanation could simply be that it needs only two collisions of $\mathrm{H}_{2} \mathrm{SO}_{4}$ with $\mathrm{HSO}_{4}{ }^{-}$to form the negative SA3, while to form the positive SA3, three molecules of sulfuric acid must add to DMA $\mathrm{H}^{+}$.

In summary, we investigated the nucleation mechanism of sulfuric acid with nitrogen bases looking at the chemical composition and the appearance time of the growing clusters in the CLOUD chamber. This is the first study we are aware of comparing the composition of positive, negative, and neutral clusters in parallel. We measured the growth process of clusters formed from a proton donor (acids) and proton acceptor (bases) by three mass spectrometers to observe the same process from different perspectives. This gives us much more confidence in the understanding of the nucleation process where acids and bases are involved. In the case of acid-base nucleation, the mechanism driving the growth of clusters is the addition of acids and bases at a close to $1: 1$ acid-base ratio. These results are confirmed by data for positive, negative, and neutral clusters. This feature also occurs with all bases used in these experiments even when it was a mixture of them. During the experiments with $\mathrm{H}_{2} \mathrm{SO}_{4}$ and DMA, it was possible to not only study the chemical composition but also follow the time evolution of the cluster appearance with a time resolution of $30 \mathrm{~s}$. It was observed that clusters of all of the polarities grow at a similar rate; however there are small differences in the formation of the smallest clusters (up to the clusters containing three molecules of sulfuric acid) where the negative clusters appear more quickly.

\section{ASSOCIATED CONTENT}

\section{S Supporting Information}

Description of the CLOUD chamber and description of the mass spectrometers plus consideration about a possible artifact. This material is available free of charge via the Internet at http://pubs. acs.org/.

\section{AUTHOR INFORMATION}

\section{Corresponding Author}

*E-mail: urs.baltensperger@psi.ch. Phone: +41(0)563102408. Fax: $+41(0) 563104525$.

\section{Notes}

The authors declare no competing financial interest.

\section{ACKNOWLEDGMENTS}

We would like to thank CERN for supporting CLOUD with important technical and financial resources, and for providing a particle beam from the CERN Proton Synchrotron. We also thank P. Carrie, L.-P. De Menezes, J. Dumollard, K. Ivanova, F. Josa, I. Krasin, R. Kristic, A. Laassiri, O.S. Maksumov, B. Marichy, H. Martinati, S.V. Mizin, R. Sitals, A. Wasem, and M. Wilhelmsson for their important contributions to the experiment and the tofTools team for support in mass spectrometry data analysis. This research has received funding from the EC Seventh Framework Programme (Marie Curie Initial Training Network “CLOUD-ITN" no. 215072, MC-ITN “CLOUD-TRAIN" no. 316662, ERC-Starting "MOCAPAF” grant no. 57360 and ERCAdvanced “ATMNUCLE” grant no. 227463), the German Federal Ministry of Education and Research (project nos. 01LK0902A and 01LK1222A), the Swiss National Science Foundation (project nos. 200020_135307 and 206620_141278), the Academy of Finland (Center of Excellence project no. 1118615), the Academy of Finland (135054, 133872, 251427, 139656, 139995, 137749, 141217, 141451, 138951), the Finnish Funding Agency for Technology and Innovation, the V.is.l. Foundation, the Nessling Foundation, the Austrian Science Fund (FWF; project no. J3198N21), the Portuguese Foundation for Science and Technology (project no. CERN/FP/116387/2010), the Swedish Research Council, Vetenskapsrådet (grant 2011-5120), the Presidium of the Russian Academy of Sciences and Russian, Foundation for Basic Research (grants 08-02-91006-CERN and 12-02-91522-CERN), the U.S. National Science Foundation (grants AGS1136479 and CHE1012293), the PEGASOS project funded by the European Commission under the Framework Programme 7 (FP7-ENV2010-265148), and the Davidow Foundation.

\section{REFERENCES}

(1) Kulmala, M.; Kontkanen, J.; Junninen, H.; Lehtipalo, K.; Manninen, H. E.; Nieminen, T.; Petäjä, T.; Sipilä, M.; Schobesberger, S.; Rantala, P.; Franchin, A.; Jokinen, T.; Jarvinen, E.; Äijälä, M.; Kangasluoma, J.; Hakala, J.; Aalto, P. P.; Paasonen, P.; Mikkila, J.; Vanhanen, J.; Aalto, J.; Hakola, H.; Makkonen, U.; Ruuskanen, T.; Mauldin, R. L.; Duplissy, J.; Vehkamäki, H.; Back, J.; Kortelainen, A.; Riipinen, I.; Kurten, T.; Johnston, M. V.; Smith, J. N.; Ehn, M.; Mentel, T. F.; Lehtinen, K. E. J.; Laaksonen, A.; Kerminen, V. M.; Worsnop, D. R. Direct Observations of Atmospheric Aerosol Nucleation. Science 2013, 339 (6122), 943-946.

(2) Kulmala, M.; Riipinen, I.; Sipilä, M.; Manninen, H. E.; Petäjä, T.; Junninen, H.; Dal Maso, M.; Mordas, G.; Mirme, A.; Vana, M.; Hirsikko, A.; Laakso, L.; Harrison, R. M.; Hanson, I.; Leung, C.; Lehtinen, K. E. J.; Kerminen, V. M. Toward direct measurement of atmospheric nucleation. Science 2007, 318 (5847), 89-92.

(3) Zhang, R. Y.; Khalizov, A.; Wang, L.; Hu, M.; Xu, W. Nucleation and Growth of Nanoparticles in the Atmosphere. Chem. Rev. 2012, 112 (3), 1957-2011.

(4) Kuang, C.; McMurry, P. H.; McCormick, A. V. Determination of cloud condensation nuclei production from measured new particle formation events. Geophys. Res. Lett. 2009, 36, 5.

(5) Merikanto, J.; Spracklen, D. V.; Mann, G. W.; Pickering, S. J.; Carslaw, K. S. Impact of nucleation on global CCN. Atmos. Chem. Phys. 2009, 9 (21), 8601-8616.

(6) Laaksonen, A.; Kulmala, M.; Berndt, T.; Stratmann, F.; Mikkonen, S.; Ruuskanen, A.; Lehtinen, K. E. J.; Dal Maso, M.; Aalto, P.; Petäjä, T.; Riipinen, I.; Sihto, S. L.; Janson, R.; Arnold, F.; Hanke, M.; Ucker, J.; Umann, B.; Sellegri, K.; O’Dowd, C. D.; Viisanen, Y. $\mathrm{SO}_{2}$ oxidation products other than $\mathrm{H}_{2} \mathrm{SO}_{4}$ as a trigger of new particle formation. Part 2: Comparison of ambient and laboratory measurements, and atmospheric implications. Atmos. Chem. Phys. 2008, 8 (23), 7255-7264.

(7) Young, L. H.; Benson, D. R; Kameel, F. R.; Pierce, J. R.; Junninen, H.; Kulmala, M.; Lee, S. H. Laboratory studies of $\mathrm{H}_{2} \mathrm{SO}_{4} / \mathrm{H}_{2} \mathrm{O}$ binary homogeneous nucleation from the $\mathrm{SO}_{2}+\mathrm{OH}$ reaction: evaluation of the experimental setup and preliminary results. Atmos. Chem. Phys. 2008, 8 (16), 4997-5016.

(8) Sorokin, A.; Arnold, F. Laboratory study of cluster ions formation in $\mathrm{H}_{2} \mathrm{SO}_{4}-\mathrm{H}_{2} \mathrm{O}$ system: Implications for threshold concentration of gaseous $\mathrm{H}_{2} \mathrm{SO}_{4}$ and ion-induced nucleation kinetics. Atmos. Environ. 2007, 41 (18), 3740-3747.

(9) Ball, S. M.; Hanson, D. R.; Eisele, F. L.; McMurry, P. H. Laboratory studies of particle nucleation: Initial results for $\mathrm{H}_{2} \mathrm{SO}_{4}, \mathrm{H}_{2} \mathrm{O}$, and $\mathrm{NH}_{3}$ vapors. J. Geophys. Res. Atmos. 1999, 104 (D19), 23709-23718.

(10) Bzdek, B. R.; DePalma, J. W.; Ridge, D. P.; Laskin, J.; Johnston, M. V. Fragmentation energetics of clusters relevant to atmospheric new particle formation. J. Am. Chem. Soc. 2013, 135 (8), 3276-3285.

(11) Kirkby, J.; Curtius, J.; Almeida, J.; Dunne, E.; Duplissy, J.; Ehrhart, S.; Franchin, A.; Gagne, S.; Ickes, L.; Kürten, A.; Kupc, A.; Metzger, A.; Riccobono, F.; Rondo, L.; Schobesberger, S.; Tsagkogeorgas, G.; Wimmer, D.; Amorim, A.; Bianchi, F.; Breitenlechner, M.; David, A.; Dommen, J.; Downard, A.; Ehn, M.; Flagan, R. C.; Haider, S.; Hansel, A.; Hauser, D.; Jud, W.; Junninen, H.; Kreissl, F.; Kvashin, A.; Laaksonen, 
A.; Lehtipalo, K.; Lima, J.; Lovejoy, E. R.; Makhmutov, V.; Mathot, S.; Mikkila, J.; Minginette, P.; Mogo, S.; Nieminen, T.; Onnela, A.; Pereira, P.; Petäjä, T.; Schnitzhofer, R.; Seinfeld, J. H.; Sipilä, M.; Stozhkov, Y.; Stratmann, F.; Tome, A.; Vanhanen, J.; Viisanen, Y.; Vrtala, A.; Wagner, P. E.; Walther, H.; Weingartner, E.; Wex, H.; Winkler, P. M.; Carslaw, K. S.; Worsnop, D. R.; Baltensperger, U.; Kulmala, M. Role of sulphuric acid, ammonia and galactic cosmic rays in atmospheric aerosol nucleation. Nature 2011, 476 (7361), 429-433.

(12) DePalma, J. W.; Bzdek, B. R.; Doren, D. J.; Johnston, M. V. Structure and energetics of nanometer size clusters of sulfuric acid with ammonia and dimethylamine. J. Phys. Chem. A 2012, 116 (3), 10301040.

(13) Bzdek, B. R.; Zordan, C. A.; Pennington, M. R.; Luther, G. W.; Johnston, M. V. Quantitative assessment of the sulfuric acid contribution to new particle growth. Environ. Sci. Technol. 2012, 46 (8), 4365-4373.

(14) Kuang, C.; Chen, M.; Zhao, J.; Smith, J.; McMurry, P. H.; Wang, J. Size and time-resolved growth rate measurements of 1 to $5 \mathrm{~nm}$ freshly formed atmospheric nuclei. Atmos. Chem. Phys. 2012, 12 (7), 35733589.

(15) Kurten, T.; Loukonen, V.; Vehkamäki, H.; Kulmala, M. Amines are likely to enhance neutral and ion-induced sulfuric acid-water nucleation in the atmosphere more effectively than ammonia. Atmos. Chem. Phys. 2008, 8 (14), 4095-4103.

(16) Almeida, J.; Schobesberger, S.; Kürten, A.; Ortega, I. K.; Kupiainen-Määttä, O.; Praplan, A. P.; Adamov, A.; Amorim, A.; Bianchi, F.; Breitenlechner, M.; David, A.; Dommen, J.; Donahue, N. M.; Downard, A.; Dunne, E.; Duplissy, J.; Ehrhart, S.; Flagan, R. C.; Franchin, A.; Guida, R.; Hakala, J.; Hansel, A.; Heinritzi, M.; Henschel, H.; Jokinen, T.; Junninen, H.; Kajos, M.; Kangasluoma, J.; Keskinen, H.; Kupc, A.; Kurten, T.; Kvashin, A. N.; Laaksonen, A.; Lehtipalo, K.; Leiminger, M.; Leppa, J.; Loukonen, V.; Makhmutov, V.; Mathot, S.; McGrath, M. J.; Nieminen, T.; Olenius, T.; Onnela, A.; Petäjä, T.; Riccobono, F.; Riipinen, I.; Rissanen, M.; Rondo, L.; Ruuskanen, T.; Santos, F. D.; Sarnela, N.; Schallhart, S.; Schnitzhofer, R.; Seinfeld, J. H.; Simon, M.; Sipilä, M.; Stozhkov, Y.; Stratmann, F.; Tome, A.; Troestl, J.; Tsagkogeorgas, G.; Vaattovaara, P.; Viisanen, Y.; Virtanen, A.; Vrtala, A.; Wagner, P. E.; Weingartner, E.; Wex, H.; Williamson, C.; Wimmer, D.; Ye, P.; Yli-Juuti, T.; Carslaw, K. S.; Kulmala, M.; Curtius, J.; Baltensperger, U.; Worsnop, D. R.; Vehkamäki, H.; Kirkby, J. Molecular understanding of sulphuric acid-amine particle nucleation in the atmosphere. Nature 2013, 502 (7471), 359-363.

(17) Bzdek, B. R.; Ridge, D. P.; Johnston, M. V. Amine exchange into ammonium bisulfate and ammonium nitrate nuclei. Atmos. Chem. Phys. 2010, 10 (8), 3495-3503.

(18) Junninen, H.; Ehn, M.; Petää, T.; Luosujarvi, L.; Kotiaho, T.; Kostiainen, R.; Rohner, U.; Gonin, M.; Fuhrer, K.; Kulmala, M.; Worsnop, D. R. A high-resolution mass spectrometer to measure atmospheric ion composition. Atmos. Meas. Technol. 2010, 3 (4), 10391053.

(19) Schobesberger, S.; Junninen, H.; Bianchi, F.; Lonn, G.; Ehn, M.; Lehtipalo, K.; Dommen, J.; Ehrhart, S.; Ortega, I. K.; Franchin, A.; Nieminen, T.; Riccobono, F.; Hutterli, M.; Duplissy, J.; Almeida, J.; Amorim, A.; Breitenlechner, M.; Downard, A. J.; Dunne, E. M.; Flagan, R. C.; Kajos, M.; Keskinen, H.; Kirkby, J.; Kupc, A.; Kürten, A.; Kurten, T.; Laaksonen, A.; Mathot, S.; Onnela, A.; Praplan, A. P.; Rondo, L.; Santos, F. D.; Schallhart, S.; Schnitzhofer, R.; Sipilä, M.; Tome, A.; Tsagkogeorgas, G.; Vehkamäki, H.; Wimmer, D.; Baltensperger, U.; Carslaw, K. S.; Curtius, J.; Hansel, A.; Petäjä, T.; Kulmala, M.; Donahue, N. M.; Worsnop, D. R. Molecular understanding of atmospheric particle formation from sulfuric acid and large oxidized organic molecules. Proc. Natl. Acad. Sci. U. S. A. 2013, 110 (43), 17223-17228.

(20) Schobesberger, S.; Franchin, A.; Bianchi, F.; Rondo, L.; Duplissy, J.; Kürten, A.; Ortega, I. K.; Metzger, A.; Schnitzhofer, R.; Almeida, J.; Amorim, A.; Dommen, J.; Dunne, E. M.; Ehn, M.; Gagné, S.; Ickes, L.; Junninen, H.; Hansel, A.; Kerminen, V. M.; Kirkby, J.; Kupc, A.; Laaksonen, A.; Lehtipalo, K.; Mathot, S.; Onnela, A.; Petäjä, T.; Riccobono, F.; Santos, F. D.; Sipilä, M.; Tomé, A.; Tsagkogeorgas, G.; Viisanen, Y.; Wagner, P. E.; Wimmer, D.; Curtius, J.; Donahue, N. M.;
Baltensperger, U.; Kulmala, M.; Worsnop, D. R. On the composition of ammonia-sulfuric acid clusters during aerosol particle formation. Atmos. Chem. Phys. 2014, in press.

(21) Kürten, A.; Jokinen, T.; Simon, M.; Sipilä, M.; Sarnela, N.; Juninnen, H.; Adamov, A.; João Almeida, A.; Amorim, A.; Bianchi, F.; Breitenlechner, M.; Dommen, J.; Donahue, N. M.; Duplissy, J.; Ehrhart, S.; Flagan, R. C.; Franchin, A.; Hakala, J.; Hansel, A.; Heinritzi, M.; Hutterli, M.; Kangasluoma, J.; Kirkby, J.; Laaksonen, A.; Lehtipalo, K.; Leiminger, M.; Makhmutov, V.; Mathot, S.; Onnela, A.; Petäjä, T.; Praplan, A. P.; Riccobono, F.; Rissanen, M. P.; Rondo, L.; Schobesberger, S.; Seinfeld, J. H.; Steiner, G.; Tomé, A.; Tröstl, J.; Winkler, P. M.; Williamson, C.; Wimmer, D.; Ye, P.; Baltensperger, U.; Carslaw, K. S.; Kulmala, M.; Worsnop, D. R.; Curtius, J. Neutral molecular cluster formation of sulfuric acid-dimethylamine observed in real time under atmospheric conditions. Proc. Natl. Acad. Sci. U. S. A. 2014, 111, 15019-15024, DOI: 10.1073/pnas.1404853111.

(22) Froyd, K. D.; Lovejoy, E. R. Bond energies and structures of ammonia-sulfuric acid positive cluster ions. J. Phys. Chem. A 2012, 116 (24), 5886-5899.

(23) Leverentz, H. R.; Siepmann, J. I.; Truhlar, D. G.; Loukonen, V.; Vehkamäki, H. Energetics of atmospherically implicated clusters made of sulfuric acid, ammonia, and dimethyl amine. J. Phys. Chem. A 2013, 117 (18), 3819-3825.

(24) Loukonen, V.; Kuo, I. F. W.; McGrath, M. J.; Vehkamäki, H. On the stability and dynamics of (sulfuric acid)(ammonia) and (sulfuric acid)(dimethylamine) clusters: A first-principles molecular dynamics investigation. Chem. Phys. 2014, 428 (0), 164-174.

(25) Hunter, E. P. L.; Lias, S. G. Evaluated gas phase basicities and proton affinities of molecules: An update. J. Phys. Chem. Ref. Data 1998, 27 (3), 413-656.

(26) Westervelt, D. M.; Pierce, J. R.; Riipinen, I.; Trivitayanurak, W.; Hamed, A.; Kulmala, M.; Laaksonen, A.; Decesari, S.; Adams, P. J. Formation and growth of nucleated particles into cloud condensation nuclei: model-measurement comparison. Atmos. Chem. Phys. 2013, 13 (15), 7645-7663.

(27) Praplan, A. P.; Bianchi, F.; Dommen, J.; Baltensperger, U. Dimethylamine and ammonia measurements with ion chromatography during the CLOUD4 campaign. Atmos. Meas. Technol. 2012, 5 (9), 2161-2167.

(28) Donahue, N. M.; Ortega, I. K.; Chuang, W.; Riipinen, I.; Riccobono, F.; Schobesberger, S.; Dommen, J.; Baltensperger, U.; Kulmala, M.; Worsnop, D. R; Vehkamäki, H. How do organic vapors contribute to new-particle formation? Faraday Discuss. 2013, 165, 91104.

(29) Ehrhart, S.; Curtius, J. Influence of aerosol lifetime on the interpretation of nucleation experiments with respect to the first nucleation theorem. Atmos. Chem. Phys. 2013, 13 (22), 11465-11471.

(30) Ehn, M.; Junninen, H.; Petäjä, T.; Kurten, T.; Kerminen, V. M.; Schobesberger, S.; Manninen, H. E.; Ortega, I. K.; Vehkamäki, H.; Kulmala, M.; Worsnop, D. R. Composition and temporal behavior of ambient ions in the boreal forest. Atmos. Chem. Phys. 2010, 10 (17), $8513-8530$

(31) Ortega, I. K.; Olenius, T.; Kupiainen-Määttä, O.; Loukonen, V.; Kurtén, T.; Vehkamäki, H. Electrical charging changes the composition of sulfuric acid-ammonia/dimethylamine clusters. Atmos. Chem. Phys. 2014, 14 (15), 7995-8007.

(32) Olenius, T.; Schobesberger, S.; Kupiainen-Maatta, O.; Franchin, A.; Junninen, H.; Ortega, I. K.; Kurten, T.; Loukonen, V.; Worsnop, D. R.; Kulmala, M.; Vehkamäki, H. Comparing simulated and experimental molecular cluster distributions. Faraday Discuss. 2013, 165, 75-89.

(33) Ortega, I. K.; Kupiainen, O.; Kurten, T.; Olenius, T.; Wilkman, O.; McGrath, M. J.; Loukonen, V.; Vehkamäki, H. From quantum chemical formation free energies to evaporation rates. Atmos. Chem. Phys. 2012, 12 (1), 225-235.

(34) Keskinen, H.; Virtanen, A.; Joutsensaari, J.; Tsagkogeorgas, G.; Duplissy, J.; Schobesberger, S.; Gysel, M.; Riccobono, F.; Slowik, J. G.; Bianchi, F.; Yli-Juuti, T.; Lehtipalo, K.; Rondo, L.; Breitenlechner, M.; Kupc, A.; Almeida, J.; Amorim, A.; Dunne, E. M.; Downard, A. J.; Ehrhart, S.; Franchin, A.; Kajos, M. K.; Kirkby, J.; Kürten, A.; Nieminen, 
T.; Makhmutov, V.; Mathot, S.; Miettinen, P.; Onnela, A.; Petäjä, T.; Praplan, A.; Santos, F. D.; Schallhart, S.; Sipilä, M.; Stozhkov, Y.; Tomé, A.; Vaattovaara, P.; Wimmer, D.; Prevot, A.; Dommen, J.; Donahue, N. M.; Flagan, R. C.; Weingartner, E.; Viisanen, Y.; Riipinen, I.; Hansel, A.; Curtius, J.; Kulmala, M.; Worsnop, D. R.; Baltensperger, U.; Wex, H.; Stratmann, F.; Laaksonen, A. Evolution of particle composition in CLOUD nucleation experiments. Atmos. Chem. Phys. 2013, 13 (11), $5587-5600$.

(35) Hanson, D. R.; Eisele, F. L. Measurement of prenucleation molecular clusters in the $\mathrm{NH}_{3}, \mathrm{H}_{2} \mathrm{SO}_{4}, \mathrm{H}_{2} \mathrm{O}$ system. J. Geophys. Res.Atmos. 2002, 107 (D12), 18.

(36) Ehn, M.; Junninen, H.; Schobesberger, S.; Manninen, H. E.; Franchin, A.; Sipilä, M.; Petäjä, T.; Kerminen, V. M.; Tammet, H.; Mirme, A.; Mirme, S.; Horrak, U.; Kulmala, M.; Worsnop, D. R. An instrumental comparison of mobility and mass measurements of atmospheric small ions. Aerosol Sci. Technol. 2011, 45 (4), 522-532.

(37) Riccobono, F.; Schobesberger, S.; Scott, C. E.; Dommen, J.; Ortega, I. K.; Rondo, L.; Almeida, J.; Amorim, A.; Bianchi, F.; Breitenlechner, M.; David, A.; Downard, A.; Dunne, E. M.; Duplissy, J.; Ehrhart, S.; Flagan, R. C.; Franchin, A.; Hansel, A.; Junninen, H.; Kajos, M.; Keskinen, H.; Kupc, A.; Kürten, A.; Kvashin, A. N.; Laaksonen, A.; Lehtipalo, K.; Makhmutov, V.; Mathot, S.; Nieminen, T.; Onnela, A.; Petäjä, T.; Praplan, A. P.; Santos, F. D.; Schallhart, S.; Seinfeld, J. H.; Sipilä, M.; Spracklen, D. V.; Stozhkov, Y.; Stratmann, F.; Tomé, A.; Tsagkogeorgas, G.; Vaattovaara, P.; Viisanen, Y.; Vrtala, A.; Wagner, P. E.; Weingartner, E.; Wex, H.; Wimmer, D.; Carslaw, K. S.; Curtius, J.; Donahue, N. M.; Kirkby, J.; Kulmala, M.; Worsnop, D. R.; Baltensperger, $\mathrm{U}$. Oxidation products of biogenic emissions contribute to nucleation of atmospheric particles. Science 2014, 344, 717-721, DOI: $10.1126 /$ science. 1243527.

(38) Su, T.; Chesnavich, W. J. Parametrization of the ion-polar molecule collision rate constant by trajectory calculations. J. Chem. Phys. 1982, 76 (10), 5183-5185.

(39) Olenius, T.; Kupiainen-Maatta, O.; Ortega, I. K.; Kurten, T.; Vehkamäki, H. Free energy barrier in the growth of sulfuric acidammonia and sulfuric acid-dimethylamine clusters. J. Chem. Phys. 2013, 139 (8), 12.

(40) Brockmann, J. E.; McMurry, P. H.; Liu, B. Y. H. Experimental study of simultaneous coagulation and diffusional loss of free-molecule aerosols in turbulent pipe-flow. J. Colloid Interface Sci. 1982, 88 (2), $522-529$. 